\title{
Silicon Alleviates Changes in the Source-Sink Relationship of Wheat Plants Infected by Pyricularia oryzae
}

\author{
Marcela Uli Peixoto Araújo, Jonas Alberto Rios, Ernesto Ticiano Silva, and Fabrício Ávila Rodrigues† \\ Laboratório da Interação Planta-Patógeno, Departamento de Fitopatologia, Universidade Federal de Viçosa, Viçosa, Minas Gerais State \\ 36570-900, Brazil \\ Accepted for publication 19 February 2019.
}

\begin{abstract}
Blast, caused by Pyricularia oryzae, has become a devastating disease on wheat in several countries worldwide. Growers need alternative methods for blast management, and silicon ( $\mathrm{Si}$ ) stands out for its potential to decrease the intensity of important diseases in several crops. This study investigated the effect of $\mathrm{Si}$ on improving photoassimilate production on flag leaves of wheat plants and their partitioning to spikes in a scenario where blast symptoms decreased as a result of potentiation of defense mechanisms by Si. Wheat plants (cultivar BRS Guamirim) were grown in hydroponic culture with 0 or $2 \mathrm{mM} \mathrm{Si}$ and inoculated with $P$. oryzae at 10 days after anthesis. The Si concentration on flag leaves and spikes of Si-supplied plants increased and resulted in lower blast symptoms. High concentrations of total soluble phenols and lignin-thioglycolic acid derivatives and greater peroxidase, polyphenoloxidase, phenylalanine ammonia-lyase, $\beta$-1,3-glucanase, and chitinase activity occurred on flag

plants not supplied with $\mathrm{Si}$ was impaired for chlorophyll $a$ fluorescence parameters including maximal photosystem II quantum efficiency, fraction of energy absorbed used in photochemistry, quantum yield of nonregulated energy dissipation, and quantum yield of regulated energy dissipation. The concentration of soluble sugars was lower on infected flag leaves and spikes from plants not supplied with $\mathrm{Si}$, whereas the hexose-to-sucrose ratio increased on infected flag leaves. Sucrosephosphate synthase activity was lower and acid invertase activity was higher on flag leaves and spikes of plants not supplied with $\mathrm{Si}$, respectively, compared with Si-supplied plants. The starch concentration on spikes of Si-supplied plants increased. In conclusion, $\mathrm{Si}$ showed a beneficial effect in improving the source-sink relationship of infected flag leaves and spikes by preserving alterations in assimilate production and partitioning during the grain filling process.
\end{abstract} leaves and spikes of Si-supplied plants and increased their resistance to blast. The concentration of photosynthetic pigments decreased and the photosynthetic performance of infected flag leaves and spikes from
Keywords: foliar disease, photosynthesis, plant nutrition, Triticum aestivum $\mathrm{L}$.
Blast, caused by the hemibiotrophic fungus Pyricularia oryzae Cavara [teleomorph Magnaporthe oryzae (T. T. Hebert) M. E. Barr] is considered one of the most important diseases affecting wheat (Triticum aestivum L.) and may cause yield losses greater than $60 \%$ when susceptible cultivars are grown under favorable conditions for disease epidemics (Ceresini et al. 2018). Blast symptoms start as elliptical to round lesions on leaves and spikelets show premature bleaching. The occurrence of blast on spikes impedes the translocation of photoassimilates to the developing grains, which become shriveled, deformed, small, and of reduced weight (Ceresini et al. 2018). Studies were carried out to investigate the diversity of the P. oryzae population, obtain new strategies for disease management, and determine the disease's impact on wheat physiology and yield (Ceresini et al. 2018; Debona et al. 2014; Rios et al. 2017). Control strategies to minimize the yield losses caused by blast include the use of resistant cultivars and fungicide applications (Castroagudín et al. 2015; Ceresini et al. 2018). Alternative methods for blast management are needed to reduce yield losses caused by blast. Silicon ( $\mathrm{Si}$ ) stands out for its potential to decrease the intensity of important diseases in several crops, especially grasses and some dicots (Datnoff et al. 2007). The biochemical and physiological mechanisms involved in the potentiation of host defense mechanisms

${ }^{\dagger}$ Corresponding author: F. A. Rodrigues; fabricio@ufv.br

Funding: This study was supported by grants and a research fellowship (to F. A. Rodrigues) from the National Council for Technological and Scientific Development $(\mathrm{CNPq})$ and the Foundation for Research Support of the State of Minas Gerais (FAPEMIG) and financed in part by the Coordenação de Aperfeiçoamento de Pessoal de Nível Superior Brasil (CAPES) (Finance Code 001).

The author(s) declare no conflict of interest.

C 2019 The American Phytopathological Society by Si include high concentrations of phenolics, lignin, and phytoalexins; an increase in the activity of defense enzymes such as chitinase (CHI), $\beta$-1,3-glucanase (GLU), polyphenoloxidase (PPO), peroxidase (POX), and phenylalanine ammonia-lyase (PAL); as well as the rapid transcription of genes related to host resistance (Debona et al. 2017). Studies involving host resistance in response to pathogen infection routinely examine CHI, GLU, PPO, POX, and PAL activity as well as expression of the genes coding for these enzymes. CHI and GLU degrade the pathogen cell wall, PPO and POX are involved in the detoxification of reactive oxygen species and in oxidation of phenolics and flavonoids, and PAL is involved in the biosynthesis of phenolic compounds, flavonoids, and some phytoalexins (Rodrigues et al. 2005).

Furthermore, increased resistance of plants supplied with $\mathrm{Si}$ against pathogens has also been associated with a physical barrier that prevents or slows fungal penetration; this physical barrier is the result of an increase in the density of the long and short silicate cells in the leaf epidermis or from a thick silica layer below the cuticle, as reported for the rice-P. oryzae pathosystem (Debona et al. 2017). Lower blast severity occurred on wheat plants supplied with $\mathrm{Si}$ (Debona et al. 2017). Aucique-Pérez et al. (2014) demonstrated that although $\mathrm{Si}$ does not have a direct metabolic role in photosynthesis upon $P$. oryzae infection, the protection against blast afforded by $\mathrm{Si}$ could be translated into improved gas exchange performance and less dysfunction at the photochemical level of infected plants supplied with this element. These ameliorative effects of $\mathrm{Si}$ combined with the use of wheat cultivars with a high level of basal resistance to blast may be translated into useful tools to enhance wheat yield under environmental conditions favorable for the occurrence of severe blast epidemics.

Wheat yield is strictly dependent on the source-sink relationship, a dynamic process determined by the capacity of the source tissues to produce photoassimilates through photosynthesis as well as the 
ability of the sink tissues to convert them into starch (Tuncel and Okita 2013). Flag leaves and spikes are the main photosynthetic sources that contribute to filling out the wheat grains (Tambussi et al. 2007). The starch synthesized in the chloroplasts during the day is degraded to sucrose at night for a continuous supply of sugars for metabolism on leaves and for exportation to the sink organs (Zeeman et al. 2007). The infection of plants by pathogens of different lifestyles negatively affects their photosynthetic performance and disturbs their carbohydrate composition and partitioning within the infected tissues (Abood and Losel 2003; Gamm et al. 2011).

This study investigated the effect of $\mathrm{Si}$ on the production of photoassimilates on flag leaves and their partitioning to spikes of wheat plants in a scenario where blast symptoms decreased as a result of potentiation of host defense mechanisms.

\section{MATERIALS AND METHODS}

Nutrient solution preparation and plant growth. Plants were fertilized with a nutrient solution based on Clark (1975) containing the following: $1.04 \mathrm{mM} \mathrm{Ca}\left(\mathrm{NO}_{3}\right)_{2} \cdot 4 \mathrm{H}_{2} \mathrm{O}, 1 \mathrm{mM}$ $\mathrm{NH}_{4} \mathrm{NO}_{3}, 0.8 \mathrm{mM} \mathrm{KNO} \mathrm{KN}_{3}, 0.6 \mathrm{mM} \mathrm{MgSO} \cdot 7 \mathrm{H}_{2} \mathrm{O}, 0.069 \mathrm{mM}$ $\mathrm{KH}_{2} \mathrm{PO}_{4}, 0.931 \mathrm{mM} \mathrm{KCl}, 19 \mu \mathrm{M} \mathrm{H}_{3} \mathrm{BO}_{3}, 2 \mu \mathrm{M} \mathrm{ZnSO}_{4} \cdot 7 \mathrm{H}_{2} \mathrm{O}, 7 \mu \mathrm{M}$ $\mathrm{MnCl}_{2} \cdot 4 \mathrm{H}_{2} \mathrm{O}, 0.6 \mu \mathrm{M} \mathrm{Na} \mathrm{MoO}_{4} 0.4 \mathrm{H}_{2} \mathrm{O}, 0.5 \mu \mathrm{M} \mathrm{CuSO} \cdot 5 \mathrm{H}_{2} \mathrm{O}$, $90 \mu \mathrm{M} \mathrm{FeSO} \cdot 7 \mathrm{H}_{2} \mathrm{O}$, and $90 \mathrm{mM}$ ethylenediaminetetraacetic acid disodium (EDTA). Monosilicic acid was obtained by passing potassium silicate (PQ Corporation, São Paulo, Brazil) through a column with a cation exchange resin (Amberlite IR-120B, $\mathrm{H}^{+}$form; Sigma-Aldrich, São Paulo, Brazil) (Ma et al. 2002). Plants were supplied with 0 and $2 \mathrm{mM}$ monosilicic acid during their growth in hydroponic culture.

Wheat seeds from cultivar BRS Guamirim, considered susceptible to blast (Cruz et al. 2010), were surface sterilized in 10\% (vol/ vol) $\mathrm{NaOCl}$ for $2 \mathrm{~min}$, rinsed in sterilized water for $3 \mathrm{~min}$, and germinated on a sand substrate at $25^{\circ} \mathrm{C}$ for 7 days. The germinated seedlings were transferred to plastic pots $(20 \mathrm{~cm}$ in diameter) with a half-strength nutritive solution without Si for 7 days. After this period, plants were transferred to plastic pots (five plants per plastic pot) containing 5 liters of a nutrient solution prepared with or without the addition of monosilicic acid. The nutrient solution was changed every 4 days, and its $\mathrm{pH}$ was measured daily. $\mathrm{pH}$ was maintained at approximately 5.8 by adding $\mathrm{NaOH}$ or $\mathrm{HCl}(1 \mathrm{M})$ solutions as needed. Plants were grown in a greenhouse with a temperature of $25 \pm 3^{\circ} \mathrm{C}$, relative humidity of $70 \pm 5 \%$, and natural photosynthetically active radiation of $950 \pm 50 \mu \mathrm{mol}$ photons $\mathrm{m}^{-2} / \mathrm{s}$.

Plant inoculation with $P$. oryzae. An isolate of $P$. oryzae (UFV/DFP Po-01) obtained from spikes of wheat plants from cultivar BR-18 was used to inoculate the plants (Debona et al. 2012). Filter paper discs containing fungal mycelia were transferred
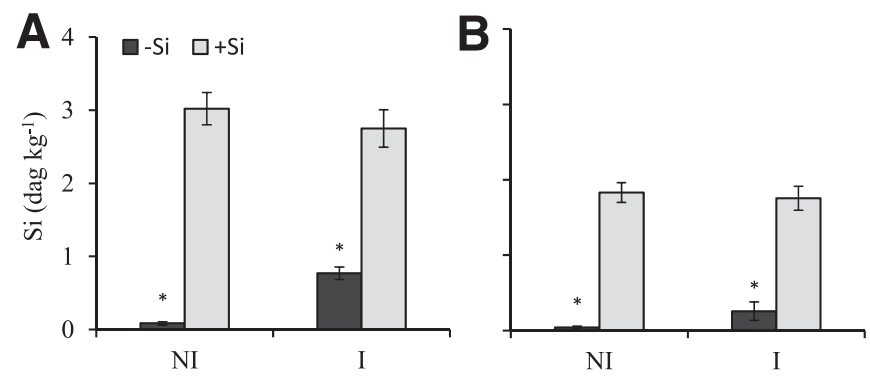

Fig. 1. Concentration of silicon (Si) on A, flag leaves and $\mathbf{B}$, spikes of wheat plants supplied with 0 or $2 \mathrm{mM} \mathrm{Si}(-\mathrm{Si}$ or $+\mathrm{Si}$, respectively) and noninoculated (NI) or inoculated (I) with Pyricularia oryzae. Means from $-\mathrm{Si}$ and $+\mathrm{Si}$ treatments followed by an asterisk for NI and I treatments are significantly different by the $F$ test $(P \leq 0.05)$. Bars represent the standard deviations of the means. $n=5$. to Petri dishes containing an oat-agar medium. After fungal mycelia growth, plugs of the medium containing fungal mycelia were transferred to new Petri dishes containing the same medium. The dishes were incubated in a growth chamber at $25^{\circ} \mathrm{C}$ with a $24-\mathrm{h}$ photoperiod for 8 days. After this period, conidia were carefully removed from the dishes with a soft bristle brush using water containing gelatin $[1 \%(\mathrm{wt} / \mathrm{vol})]$. The conidial suspension was calibrated with a hemacytometer to obtain a concentration of $1 \times 10^{5}$ conidia/ml. The conidial suspension was sprayed on the adaxial surface of the leaves and spikes of plants (growth stage 75, milk development) (Zadoks et al. 1974) with the aid of an atomizer (Paasche Airbrush Co., Chicago, IL). After inoculation, plants were kept in a mist chamber at $25^{\circ} \mathrm{C}$ for $24 \mathrm{~h}$ in the dark. Plants were transferred to a greenhouse (temperature of $25 \pm 3^{\circ} \mathrm{C}$ and relative humidity of $80 \pm 5 \%$ ) until the end of the experiments.

Blast assessment. Blast severity on the flag leaves and spikes was assessed at 48, 72, and $96 \mathrm{~h}$ after inoculation (hai). Blast severity on the flag leaves was quantified by using a visual rating, whereas severity on the spikes was quantified as the mean proportion of diseased spikelets per spike (diseased spikelets/total spikelets rated $\times 100)($ Rios et al. 2013, 2017).

Chlorophyll $\boldsymbol{a}$ fluorescence imaging. Flag leaves and spikes of plants were used to obtain images and parameters of chlorophyll $a(\mathrm{Chl} a)$ fluorescence by using the MAXI version of the ImagingPAM fluorometer and Imaging Win software (Heinz Walz $\mathrm{GmbH}$, Effeltrich, Germany) at 48, 72, and 96 hai. A charge-coupled device camera (resolution of $640 \times 480$ pixels in a visible sample area of $24 \times 32 \mathrm{~mm}$ ) was used to capture the Chl $a$ fluorescence emission transients from flag leaves and spikes following the procedures described by Aucique-Pérez et al. (2014), Rios et al. (2017), and Tatagiba et al. (2014).

Biochemical assays. Samples of flag leaves, spikes, and grains obtained from plants of each replication per treatment were collected at 48, 72, and 96 hai. Samples collected from flag leaves, spikes, and grains from noninoculated plants served as a control. To determine enzyme activity, samples were collected at 8 A.M.

Determination of photosynthetic pigments. Concentrations of $\mathrm{Chl} a, \mathrm{Chl} b$, and carotenoids were determined using dimethylsulfoxide (DMSO) as an extractor (Santos et al. 2008). Five discs of flag leaves ( $1 \mathrm{~cm}$ in diameter) were collected at 48, 72, and 96 hai, immersed in glass tubes containing $5 \mathrm{ml}$ of saturated DMSO solution and calcium carbonate $\left(\mathrm{CaCO}_{3}\right)(5 \mathrm{~g} /$ liter $)$, and kept at room temperature for $24 \mathrm{~h}$ in the dark. Absorbance of the extracts was read at 480,649, and $663 \mathrm{~nm}$ using a saturated solution of DMSO and $\mathrm{CaCO}_{3}$ as the reference.

Determination of enzymes activities. To determine the activities of acid invertase (Praxedes et al. 2006) and sucrosephosphate synthase (SPS) under saturating and limiting substrate conditions (Doehlert and Huber 1983), extract from flag leaf tissue was obtained according to Nunes-Nesi et al. (2007). A total of $0.3 \mathrm{~g}$ of flag leaf tissue was macerated using a mortar and a pestle with liquid nitrogen and $2 \%(\mathrm{wt} / \mathrm{vol})$ polyvinylpyrrolidone to obtain a fine powder, which was homogenized in $2 \mathrm{ml}$ of $100 \mathrm{mM}$ potassium phosphate $(\mathrm{pH}$ 6.8) containing $1 \mathrm{mM}$ phenylmethylsulfonyl fluoride and $0.1 \mathrm{mM}$ EDTA. The homogenized material was centrifuged and the supernatant was used for the determination of CHI, GLU, POX, PPO, and PAL activities as previously described (Debona et al. 2012). All enzyme activity measurements were performed in triplicate. The soluble protein concentration of the extracts was measured according to Bradford (1976) using bovine serum albumin as the standard protein.

Determination of carbohydrate and protein concentrations. Samples of flag leaves and grains (250 $\mathrm{mg}$ of fresh matter) were lyophilized $\left(-48^{\circ} \mathrm{C}\right)$ and ground in a cell disruptor using metal balls (3.2 $\mathrm{mm}$ in diameter) following agitation at $40 \times g$ for $5 \mathrm{~min}$ (MiniBead Beater-96; Bio Spec Products, Bartlesville, OK). Samples (15 mg) were homogenized with $600 \mu \mathrm{l}$ of $98 \%$ (vol/vol) ethanol and then incubated at $80^{\circ} \mathrm{C}$ for 20 min following centrifugation 
at $14,000 \times g$ for $5 \mathrm{~min}$. These processes were repeated after homogenizing the pellet with 80 and $50 \%$ ethanol, respectively. Sugar concentrations (glucose, fructose, and sucrose) (Gibon et al. 2004) were determined in the supernatant solutions, whereas while

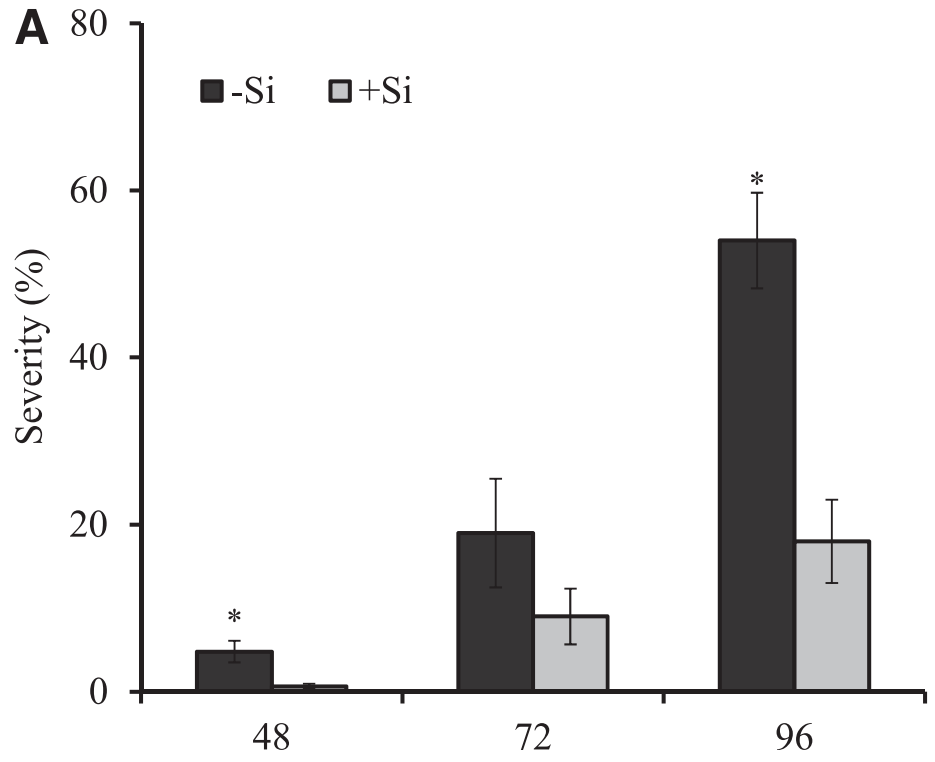

Hours after inoculation starch concentrations (Fernie et al. 2001) were determined in the insoluble fractions.

Determination of the concentrations of total soluble phenols and lignin-thioglycolic acid derivatives. A total of

B

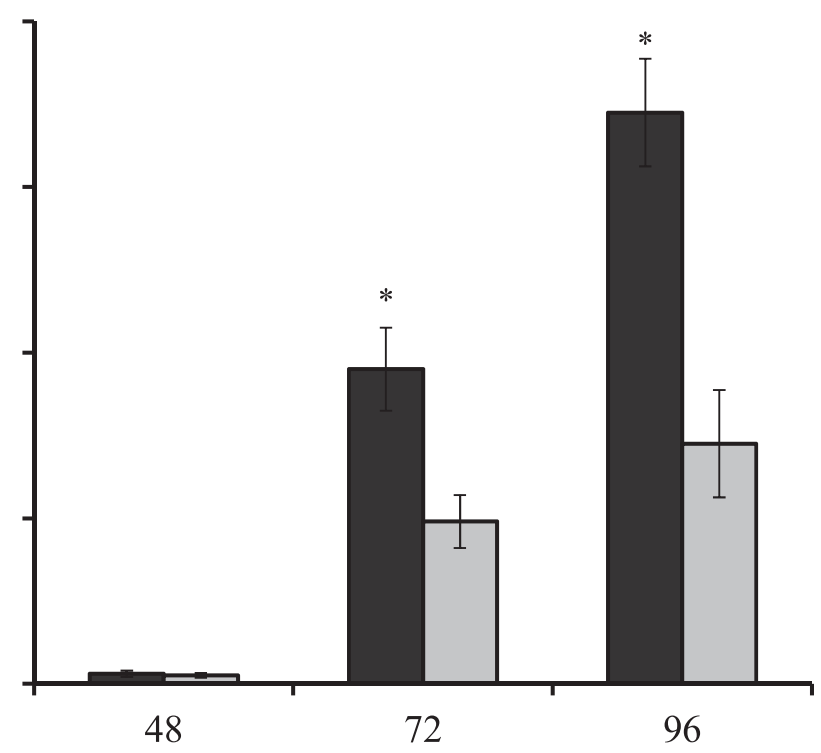

Hours after inoculation

Fig. 2. Severity of blast on A, flag leaves and $\mathbf{B}$, spikes of wheat plants supplied with 0 or $2 \mathrm{mM}$ silicon (-Si or $+\mathrm{Si}$, respectively) and inoculated with Pyricularia oryzae. Means from $-\mathrm{Si}$ and $+\mathrm{Si}$ treatments followed by an asterisk, at each evaluation time, are significantly different by the $F$ test $(P \leq 0.05)$. Bars represent the standard deviations of the means. $n=5$.

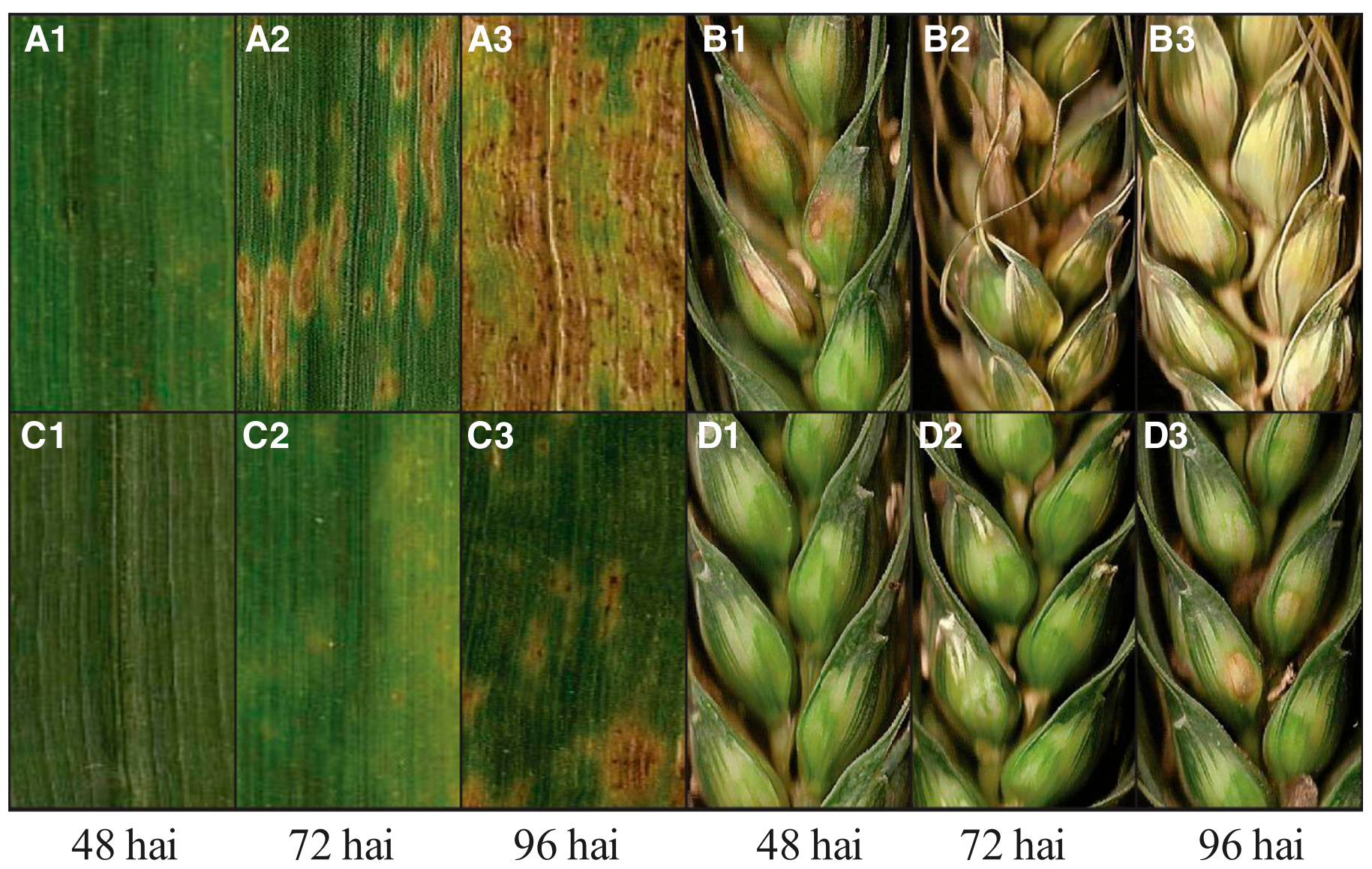

Fig. 3. Symptoms of blast on $\mathbf{A}$ and $\mathbf{C}$, flag leaves and $\mathbf{B}$ and $\mathbf{D}$, spikes of wheat plants supplied with $0 \mathrm{mM}$ silicon (-Si) (A1 to A3 and B1 to B3) or $2 \mathrm{mM} \mathrm{Si}$ (+Si) (C1 to C3 and D1 to D3) at 48, 72, and $96 \mathrm{~h}$ after inoculation (hai). 
$0.1 \mathrm{~g}$ of either flag leaves or spikes was ground into a fine powder with liquid nitrogen using a mortar and pestle and homogenized in $1 \mathrm{ml}$ of $80 \%$ ( $\mathrm{vol} / \mathrm{vol}$ ) methanol solution. The crude extract was shaken at $300 \mathrm{rpm}$ at $25^{\circ} \mathrm{C}$ for $2 \mathrm{~h}$ and the mixture was centrifuged at $17,000 \times g$ for $30 \mathrm{~min}$. The total soluble phenol (TSP) concentration was determined in the methanolic extract and the pellet was used to determine the lignin-thioglycolic acid (LTGA) derivative concentration with a few modifications (Tatagiba et al. 2014).

Determination of $\mathrm{Si}$ concentration on flag leaves and spikes. Flag leaves and spikes were collected from the plants used to evaluate blast severity, washed in deionized water, dried for $72 \mathrm{~h}$ at $65^{\circ} \mathrm{C}$, and ground to pass through a 40 -mesh screen. The $\mathrm{Si}$ concentration was determined by colorimetric analysis of $0.1 \mathrm{~g}$ of dried and alkali-digested tissue (Resende et al. 2009).

Experimental design and statistical analysis. A $2 \times 2$ factorial experiment, consisting of two Si concentrations ( 0 and $2 \mathrm{mM}$, referred to hereafter as $-\mathrm{Si}$ and $+\mathrm{Si}$ plants, respectively) and noninoculated or inoculated plants, was arranged in a completely randomized design with five replications. The experiment was repeated once. Each experimental unit corresponded to a plastic pot containing five plants. A total of 100 plants were used in each experiment (25 plants per treatment at each evaluation time). Data from all of the variables evaluated were subjected to analysis of variance (ANOVA) and the means from the treatments were compared by the $F$ test $(P \leq 0.05)$ using SAS software (SAS Institute Inc., Cary, NC). For Si concentrations on flag leaves and spikes and photosynthetic pigment concentrations, ANOVA was considered to be a $2 \times 2$ factorial experiment consisting of two Si concentrations and noninoculated or inoculated plants. For the photosynthetic measurements, ANOVA was considered to be a $2 \times 2 \times 4$ factorial experiment consisting of two Si concentrations, noninoculated or inoculated plants, and four sampling times. Pearson correlation was used to determine the relationships between $\mathrm{Si}$ concentration on flag leaves and spikes and blast severity for both $-\mathrm{Si}$ and $+\mathrm{Si}$ treatments separately.

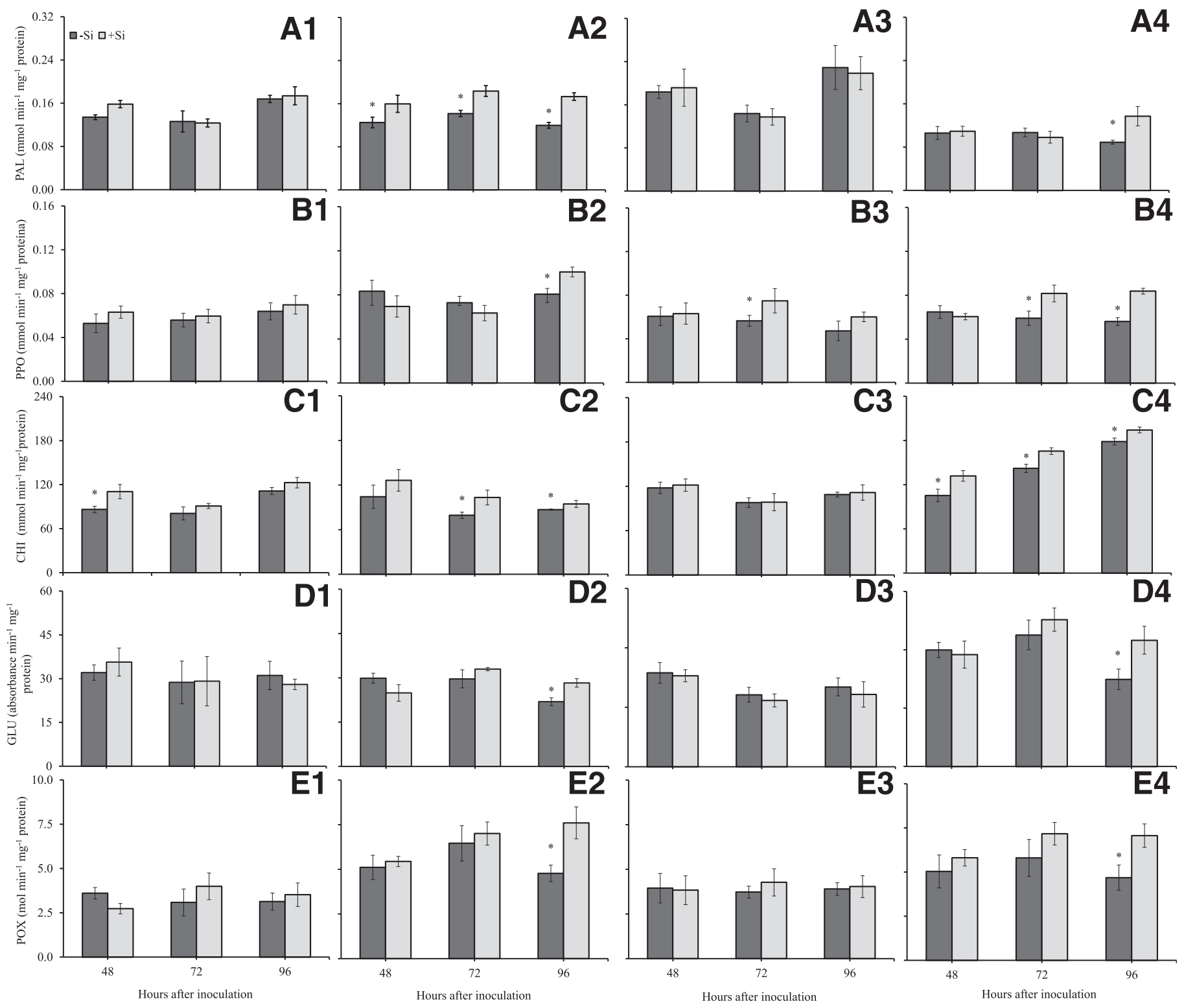

Fig. 4. Activities of A, PAL, B, PPO, C, CHI, D, GLU, and E, POX on flag leaves (images A1 to E1 and A2 to E2) and spikes (images A3 to E3 and A4 to E4) of wheat plants supplied with 0 or $2 \mathrm{mM}$ silicon (-Si or $+\mathrm{Si}$, respectively) and noninoculated (images A1 to E1 and A3 to E3) or inoculated (images A2 to E2 and A4 to E4) with Pyricularia oryzae. Means from $-\mathrm{Si}$ and $+\mathrm{Si}$ treatments followed by an asterisk, at each sampling time, are significantly different by the $F$ test $(P \leq 0.05)$. Bars represent the standard deviations of the means. $n=5$. PAL $=$ phenylalanine ammonia-lyase, $\mathrm{PPO}=$ polyphenoloxidase, $\mathrm{CHI}=$ chitinase, GLU $=\beta-1,3$-glucanase, and $\mathrm{POX}=$ peroxidase . 


\section{RESULTS}

Si concentration on flag leaves and spikes. The Si concentration on flag leaves significantly increased by 97 and $72 \%$ for noninoculated and inoculated $+\mathrm{Si}$ plants, respectively, compared with their control counterparts (Fig. 1A). There were significant increases of 98 and $86 \%$ for the $\mathrm{Si}$ concentration on spikes of noninoculated and inoculated $+\mathrm{Si}$ plants, respectively, compared with their control counterparts (Fig. 1B).

Blast severity. For $+\mathrm{Si}$ plants, blast severity on flag leaves significantly decreased by 87 and $67 \%$ at 48 and 96 hai, respectively, compared with $-\mathrm{Si}$ plants (Fig. 2A). Blast severity on the spikes of + Si plants significantly decreased by 48 and $58 \%$ at 72 and 96 hai, respectively, compared with -Si plants (Fig. 2B). At 48 hai, small water-soaked lesions were noticed on flag leaves; from 72 to 96 hai, they expanded, became necrotic, exhibited grayish coloration, and coalesced (Fig. 3A1 to A3) in contrast with the small noncoalesced lesions that developed on flag leaves of $+\mathrm{Si}$ plants (Fig. 3C1 to C3). The gray-brown lesions caused intense tissue discoloration on the spikes of $-\mathrm{Si}$ plants (Fig. 3B1 to B3). By contrast, the spikes of $+\mathrm{Si}$ plants showed greenish coloration and elliptical lesions with light brown color in the borders and gray centers and were of small size (Fig. 3D1 to D3).

Defense enzymes activities. For flag leaves of noninoculated plants, there was no significant difference for PAL, PPO, CHI, GLU, and POX activities between $-\mathrm{Si}$ and $+\mathrm{Si}$ treatments regardless of the sampling time (Fig. 4A1, B1, C1, D1, and E1). For spikes of noninoculated plants, there was no significant difference for PAL, $\mathrm{CHI}, \mathrm{GLU}$, and POX activities between $-\mathrm{Si}$ and $+\mathrm{Si}$ treatments regardless of the sampling time (Fig. 4A3, C3, D3, and E3). At 72 hai, PPO activity significantly increased by $25 \%$ on spikes of $+\mathrm{Si}$ noninoculated plants compared with - Si noninoculated plants (Fig. 4B3). Activity on flag leaves of $+\mathrm{Si}$ inoculated plants increased by 21, 22, and $31 \%$ for PAL at 48, 72, and 96 hai; $20 \%$ for PPO at 96 hai; and 23 and $8 \%$ for $\mathrm{CHI}$ at 72 and 96 hai, respectively, compared with their control counterparts (Fig. 4A2, B2, and C2). GLU and POX activities significantly increased by 22 and $37 \%$, respectively, at 96 hai on flag leaves of $+\mathrm{Si}$ inoculated plants compared with their $-\mathrm{Si}$ counterparts (Fig. 4D2 and E2). Activity on spikes of $+\mathrm{Si}$ inoculated plants increased by $35 \%$ at 96 hai for PAL; 28 and $33 \%$ at 72 and 96 hai for PPO; 20, 14, and $8 \%$ at 48, 72, and 96 hai for CHI; and $31 \%$ at 96 hai for GLU, respectively, compared with their control counterparts (Fig. 4A4, B4, C4, and D4). At 96 hai, POX activity significantly increased by $34 \%$ on spikes of $+\mathrm{Si}$ inoculated plants compared with $-\mathrm{Si}$ inoculated plants (Fig. 4E4).

TSP concentration. For noninoculated plants, there was no significant difference in TSP concentration between $-\mathrm{Si}$ and $+\mathrm{Si}$ plants regardless of the sampling time (Fig. 5A and C). For flag leaves of inoculated plants, the TSP concentration significantly increased by 12,24 , and $22 \%$ at 48,72 , and 96 hai for +Si plants compared with -Si plants, respectively (Fig. 5B). The TSP concentration significantly decreased by $15 \%$ at 48 hai and significantly increased by 16 and $17 \%$ at 72 and 96 hai, respectively, for $+\mathrm{Si}$ plants compared with -Si plants (Fig. 5D).
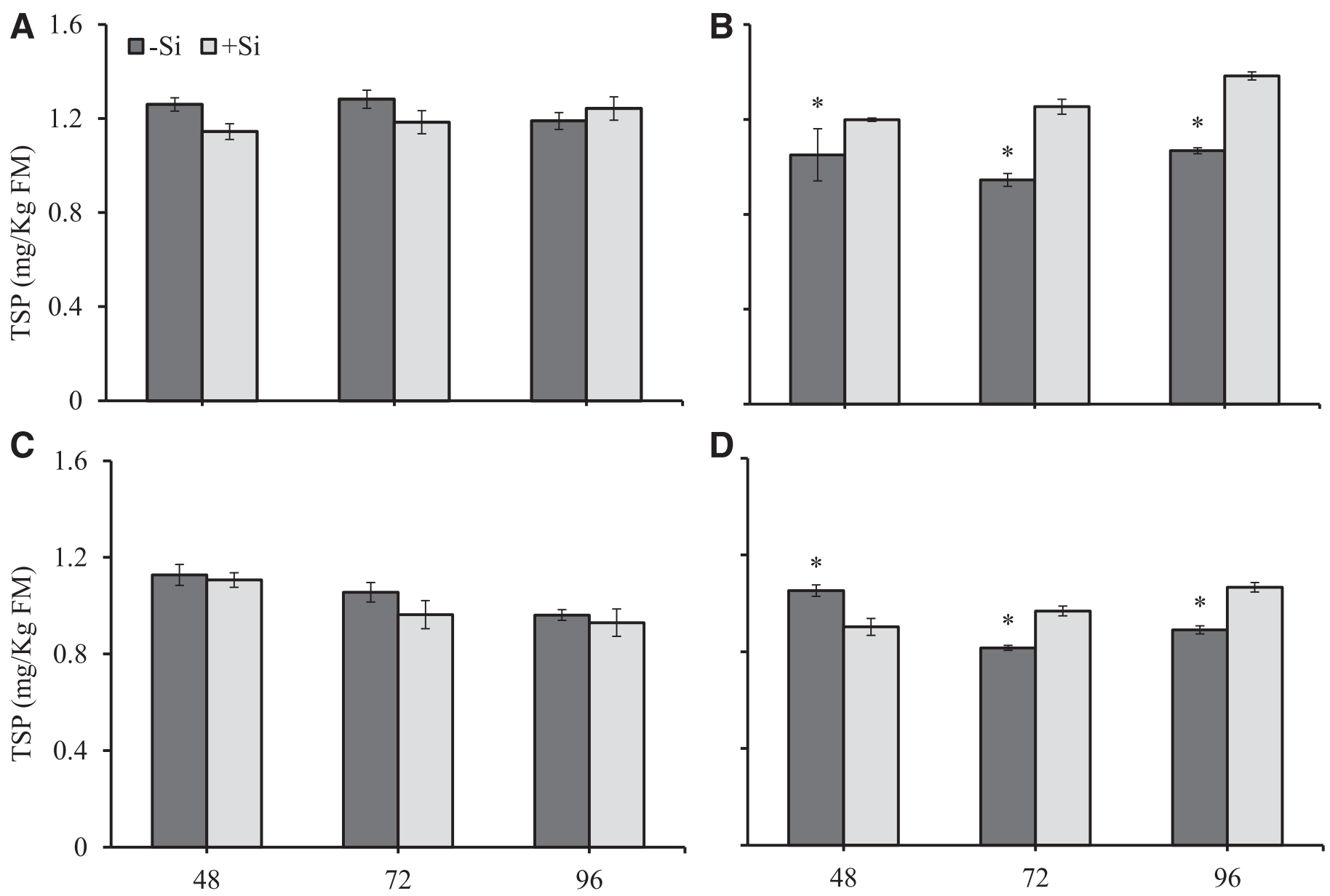

Hours after inoculation

Hours after inoculation

Fig. 5. Concentration of total soluble phenols (TSP) on A and B, flag leaves and $\mathbf{C}$ and $\mathbf{D}$, spikes of wheat plants supplied with 0 or $2 \mathrm{mM}$ silicon (-Si or $+\mathrm{Si}$, respectively) and noninoculated (A and C) or inoculated (B and D) with Pyricularia oryzae. Means from $-\mathrm{Si}$ and + Si treatments followed by an asterisk, at each sampling time, are significantly different by the $F$ test $(P \leq 0.05)$. Bars represent the standard deviations of the means. $n=5$. FM fresh matter. 
Concentration of LTGA derivatives. For flag leaves of noninoculated plants, there was no significant difference in the concentration of LTGA derivatives between $-\mathrm{Si}$ and $+\mathrm{Si}$ treatments regardless of the sampling time (Fig. 6A). The concentration of LTGA derivatives significantly increased by $42 \%$ at 96 hai for spikes of + Si plants compared with - Si plants (Fig. 6C). For flag leaves of inoculated plants, the concentration of LTGA derivatives significantly increased by 31 and $42 \%$ at 72 and 96 hai, respectively, for $+\mathrm{Si}$ plants compared with $-\mathrm{Si}$ plants (Fig. 6B). The concentration of LTGA derivatives significantly increased by $47 \%$ at 96 hai for spikes of $+\mathrm{Si}$ plants compared with $-\mathrm{Si}$ plants (Fig. 6D).

Imaging of $\mathrm{Chl} \boldsymbol{a}$ fluorescence parameters. The first visual changes in images of the following parameters were noticed at 48 hai on flag leaves and spikes of $-\mathrm{Si}$ and + Si plants: $F_{\mathrm{v}} / F_{\mathrm{m}}$, maximal photosystem II quantum yield; $F_{\mathrm{m}}$, maximal fluorescence; Y(II), fraction of energy absorbed used in photochemistry; Y(NPQ), quantum yield of regulated energy dissipation; and $\mathrm{Y}(\mathrm{NO})$, quantum yield of nonregulated energy dissipation (Fig. 7). As the lesions expanded on flag leaves and spikes of -Si plants, especially at 96 hai, there were alterations in the images of these five parameters (Fig. 7). By contrast, alterations in the images of parameters $F_{\mathrm{v}} / F_{\mathrm{m}}, F_{\mathrm{m}}, \mathrm{Y}(\mathrm{II}), \mathrm{Y}(\mathrm{NPQ})$, and $\mathrm{Y}(\mathrm{NO})$ were less evident on flag leaves and spikes of +Si plants (Fig. 7) and this pattern was likely associated with lower disease severity (Figs. 2 and 3). Changes in the images of the five parameters in the area surrounding the lesions on flag leaves and spikes of $-\mathrm{Si}$ plants were more pronounced compared with those in the flag leaves and spikes of $+\mathrm{Si}$ plants (Fig. 7). Based on the semiquantitative analysis of these Chl $a$ fluorescence parameters, there was no significant difference for $F_{\mathrm{m}}$ and $\mathrm{Y}(\mathrm{II})$ between flag leaves from $-\mathrm{Si}$ and $+\mathrm{Si}$ noninoculated plants regardless of the sampling time (Fig. 8B1 and C1). For flag leaves of noninoculated plants, Y(NPQ) significantly increased by $11 \%$ at 72 hai and decreased by $32 \%$ at 96 hai, whereas $\mathrm{Y}(\mathrm{NO})$ significantly increased by $18 \%$ at 96 hai for + Si plants compared with - Si plants (Fig. 8D1 and E1). On flag leaves of +Si inoculated plants, there were increases of 13,63 , and $28 \%$ at 48,72 , and 96 hai, respectively, for $F_{\mathrm{v}} / F_{\mathrm{m}} ; 44$ and $39 \%$ at 72 and 96 hai for $F_{\mathrm{m}} ; 28,24$, and $66 \%$ at 48,72 , and 96 hai for $\mathrm{Y}(\mathrm{II})$; and 35 and $30 \%$ at 48 and 72 hai for Y(NPQ) compared with -Si plants (Fig. 8A2, B2, C2, and D2). For flag leaves of $+\mathrm{Si}$ inoculated plants, Y(NPQ) significantly decreased by 35 and $29 \%$ at 48 and 72 hai, respectively, and increased by $21 \%$ at 96 hai, whereas $\mathrm{Y}(\mathrm{NO})$ significantly decreased by $18 \%$ at 96 hai for + Si plants compared with - Si plants (Fig. 8D2 and E2). For spikes of noninoculated plants, there was no significant difference between $-\mathrm{Si}$ and $+\mathrm{Si}$ treatments for any of the $\mathrm{Chl} a$ parameters evaluated regardless of the sampling time (Fig. 8A3, B3, $\mathrm{C} 3$, D3, and E3). On spikes of $+\mathrm{Si}$ inoculated plants, the values were significantly superior by 4,15 , and $28 \%$ at 48, 72, and 96 hai, respectively, for $F_{\mathrm{v}} / F_{\mathrm{m}} ; 72 \%$ at 96 hai for $F_{\mathrm{m}} ; 29$ and $49 \%$ at 72 and 96 hai for Y(II); and $30 \%$ at 96 hai for Y(NPQ) compared with -Si plants (Fig. 8A4, B4, C4, and D4). Y(NO) significantly decreased by 19 and $47 \%$ at 72 and 96 hai, respectively, on spikes of $-\mathrm{Si}$ inoculated plants compared with their $+\mathrm{Si}$ counterparts (Fig. 8D4 and E4).

Sucrose, fructose, and glucose concentrations. On flag leaves of $+\mathrm{Si}$ inoculated plants, there were significant increases of 28 and $44 \%$ at 72 and 96 hai, respectively, for the sucrose concentration and significant decreases of 62 and $50 \%$ and 42 and $33 \%$ for the fructose concentration and the ratio of glucose concentration at 72 and 96 hai, respectively, compared with their control counterparts (Fig. 9A2, B2, and C2). On spikes of $+\mathrm{Si}$
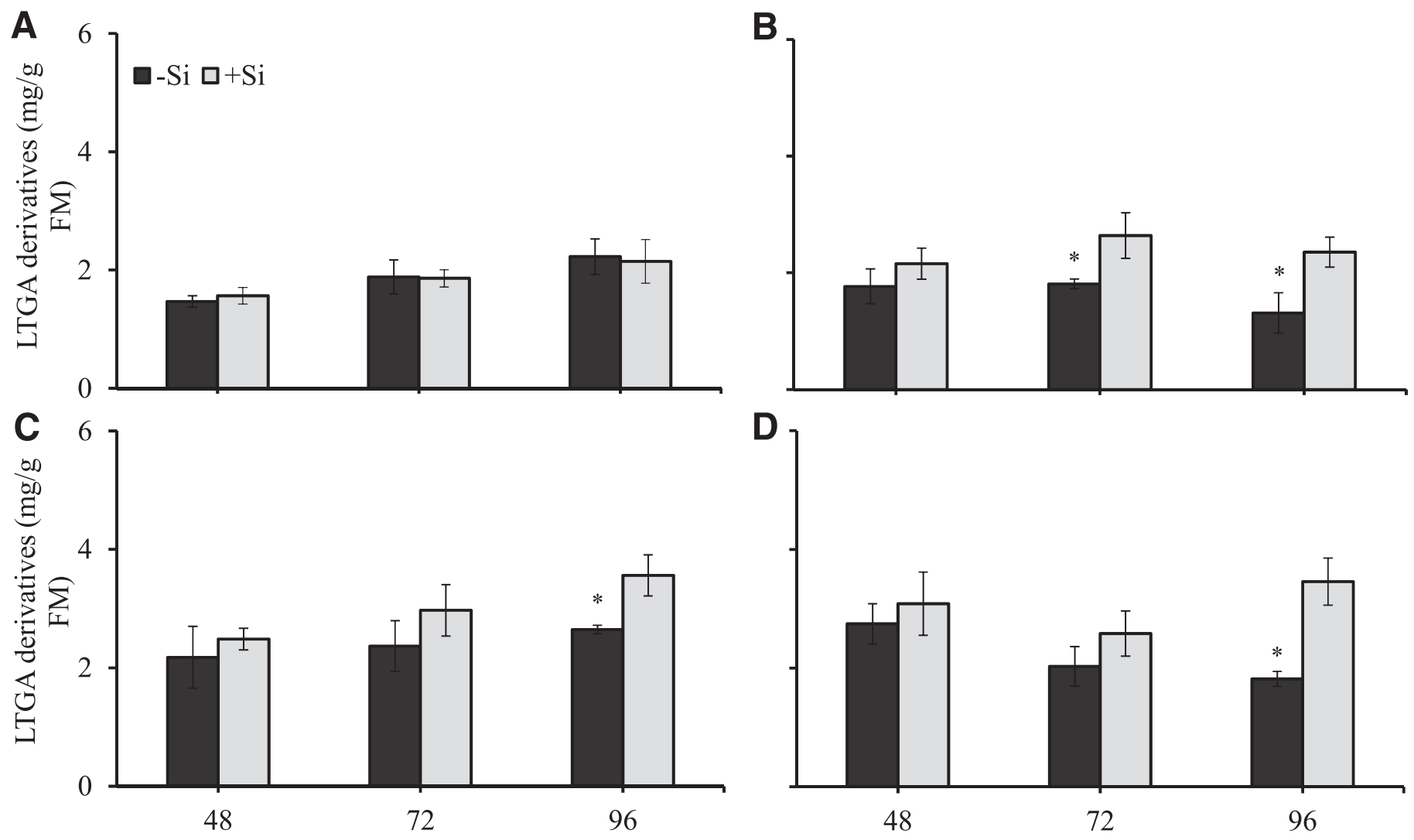

Hours after inoculation

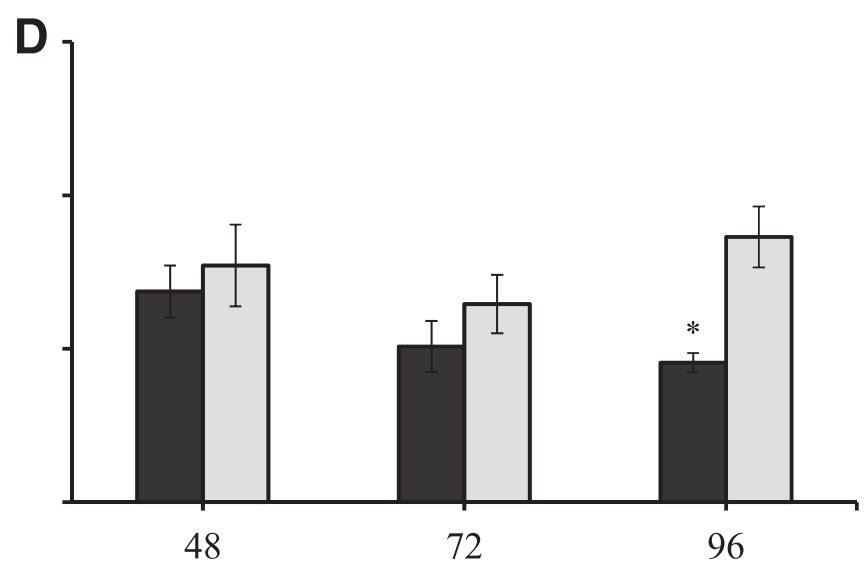

Hours after inoculation

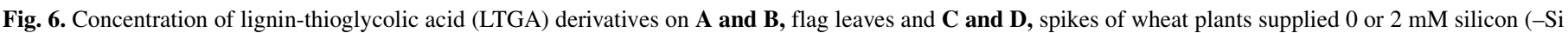

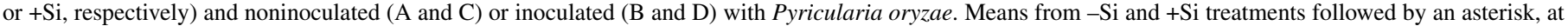
each sampling time, are significantly different by the $F$ test $(P \leq 0.05)$. Bars represent the standard deviations of the means. $n=5$. FM fresh matter. 
inoculated plants, there were significant increases of 37 and 55\% at 72 and 96 hai, respectively, for the sucrose concentration and significant decreases of $15 \%$ for the fructose concentration at 48 hai and of 74 and $50 \%$ for the glucose concentration at 72 and 96 hai, respectively, compared with their control counterparts (Fig. 9A4, B4, and C4).

Starch concentration. The starch concentration was significantly increased by $23 \%$ at 96 hai on spikes of $+\mathrm{Si}$ noninoculated plants compared with $-\mathrm{Si}$ plants (Fig. 10A). On spikes of $+\mathrm{Si}$ inoculated plants, the starch concentration was significantly increased by 26 and $31 \%$ at 72 and 96 hai, respectively, compared with -Si plants (Fig. 10B).

Concentrations of photosynthetic pigments. The concentrations of Chl $a+b$ and carotenoids were significantly increased by 13 and $12 \%$ at 48 and 72 hai, respectively, and by $20 \%$ at 72 hai on flag leaves of + Si noninoculated plants compared with their control counterparts (Fig. 11A and C). On flag leaves of $+\mathrm{Si}$ inoculated plants, the $\mathrm{Chl} a+b$ concentration significantly increased by 18 and $40 \%$ at 72 and 96 hai, respectively, and carotenoid concentration increased by $27 \%$ at 96 hai compared with their control counterparts (Fig. 11B and D).

Activities of SPS and acid invertase. For flag leaves and spikes of noninoculated plants, there was no significant difference in the activities of SPS and acid invertase between $-\mathrm{Si}$ and $+\mathrm{Si}$ treatments regardless of the sampling time (Fig. 12A1, A3, B1, and B3). On flag leaves of $+\mathrm{Si}$ inoculated plants, there were increases of 39 and $32 \%$ at 48 and 96 hai, respectively, for SPS activity and decreases of 30 and $21 \%$ at 72 and 96 hai, respectively, for acid invertase activity compared with their control counterparts (Fig. 12A2 and B2). On spikes of $+\mathrm{Si}$ inoculated plants, there were increases of 29 and $28 \%$ at 72 and 96 hai, respectively, for SPS activity and 27 and $43 \%$ at 72 and 96 hai, respectively, for acid invertase activity compared with $-\mathrm{Si}$ plants (Fig. 12A4 and B4).

\section{DISCUSSION}

This study provides novel information from a physiological and biochemical perspective regarding the effect of $\mathrm{Si}$ on enhancing wheat resistance to blast at the source-sink interface. The greater $\mathrm{Si}$ concentration on both flag leaves and spikes resulted in lower disease severity on these organs. It is plausible that Si deposition and polymerization below the cuticle of the flag leaves and on spike tissue prevented or delayed $P$. oryzae penetration. Rice resistance to $P$. oryzae infection was attributed to Si deposition below the cuticle (Debona et al. 2017). It can be postulated that wheat plants supplied with $\mathrm{Si}$ responded quickly and more efficiently against $P$. oryzae infection because in areas of heavy $\mathrm{Si}$ deposition, a delay in fungal ingress and a slowing of tissue colonization by fungal hyphae provided the wheat plants enough time to activate their defense mechanisms. The high CHI, GLU, PAL, POX, and PPO activities on flag leaves and spikes of plants supplied with Si correlates with a lower deleterious effect caused by $P$. oryzae infection. Previous studies reported that the resistance of several plant species against pathogens of different lifestyles can be potentiated by $\mathrm{Si}$ (Cruz et al. 2015; Datnoff et al. 2007; Debona et al. 2017; Resende et al. 2009). $\mathrm{CHI}$ and GLU are key enzymes involved in the host defense response against pathogen attack because they catalyze hydrolysis of the carbohydrates chitin and $\beta$-1,3-glucan, respectively, found in their cell wall (Mauch et al. 1988). CHI activity was high on the leaves of wheat plants supplied with $\mathrm{Si}$ in response to $P$. oryzae infection (Debona et al. 2017). PAL activity was of greater importance on flag leaves than on spikes of plants supplied with $\mathrm{Si}$. This enzyme catalyzes the deamination of the amino acid L-phenylalanine for the synthesis of phenols, with lignin being one possible end product (Campbell and Sederoff 1996). Therefore, the high concentrations of TSP and LTGA derivatives on the flag leaves and spikes of wheat plants were of detrimental importance for their resistance against blast. Cruz et al. (2015) reported that the colonization of $P$. oryzae in the leaf tissue of wheat plants supplied with Si was limited because of phenol deposition. It is known that phenols are associated with an increase in fungal membrane permeability, leakage of cell contents, and cytoplasm aggregation (Southerton and Deverall 1990). Reinforcement of the cell walls in both flag leaves and spikes as a result of a high concentration of LTGA derivatives protected them from the deleterious action of both hydrolytic enzymes and the nonhost selective toxins released by $P$. oryzae. The polymerization of phenols that led to an increase in tissue lignification involves the participation of both PPO and POX (Tatagiba et al. 2014). In the present study, PPO and POX activities were greater on flag leaves and spikes of plants supplied with Si. High POX and PPO activities on rice and wheat plants supplied with $\mathrm{Si}$ increased their resistance against the infections caused by Monographella albescens and $P$. oryzae, respectively (Debona et al. 2017; Tatagiba et al. 2014).

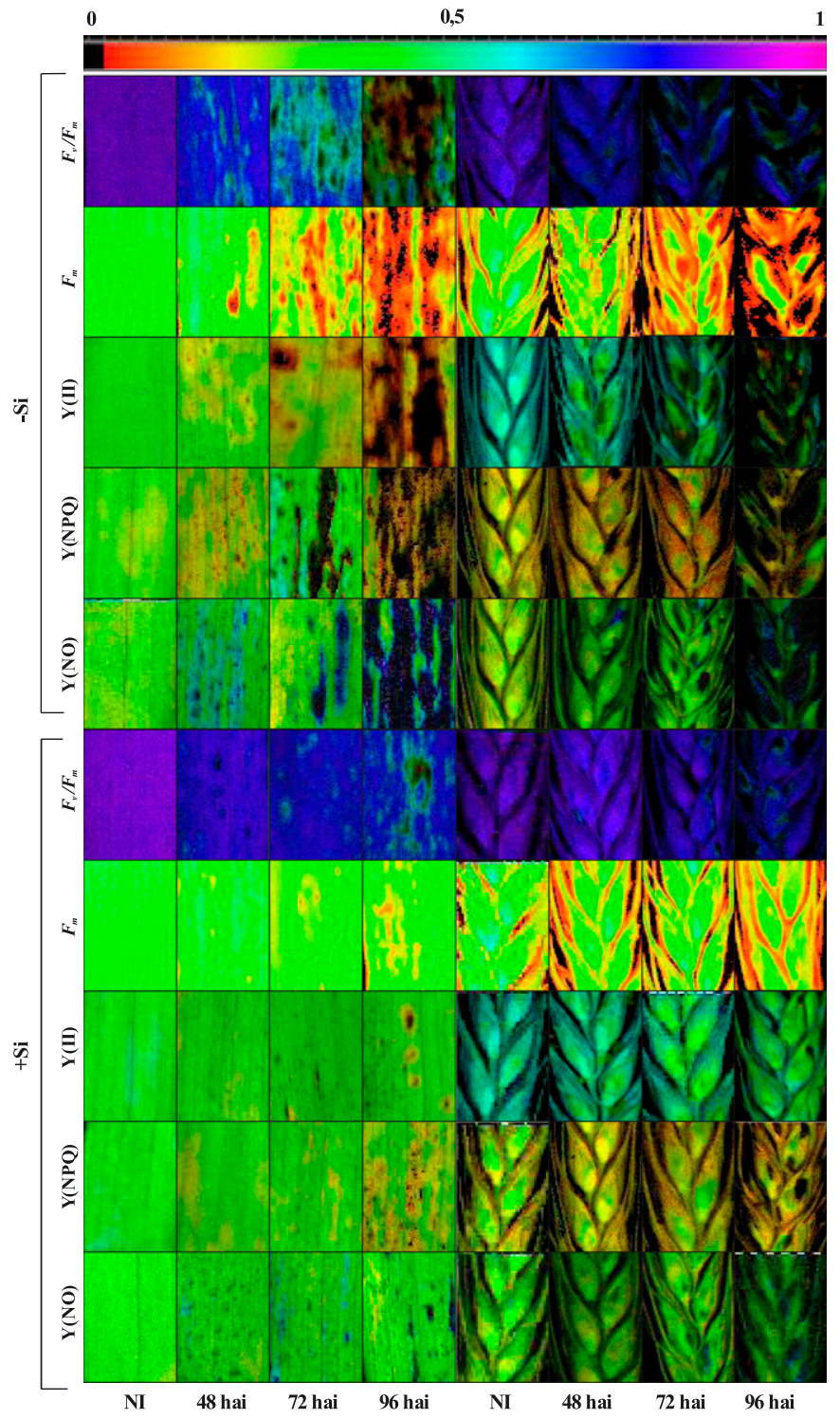

Fig. 7. $F_{\mathrm{v}} / F_{\mathrm{m}}, F_{\mathrm{m}}, \mathrm{Y}(\mathrm{II}), \mathrm{Y}(\mathrm{NPQ})$, and $\mathrm{Y}(\mathrm{NO})$ determined on flag leaves and spikes of wheat plants supplied with 0 or $2 \mathrm{mM}$ silicon $(-\mathrm{Si}$ or $+\mathrm{Si}$, respectively) and noninoculated (NI) or inoculated with Pyricularia oryzae at 48, 72, and $96 \mathrm{~h}$ after inoculation (hai). $F_{\mathrm{v}} / F_{\mathrm{m}}=$ maximal photosystem II quantum yield, $F_{\mathrm{m}}=$ maximal fluorescence, $\mathrm{Y}(\mathrm{II})=$ fraction of energy absorbed used in photochemistry, $\mathrm{Y}(\mathrm{NPQ})$ = quantum yield of regulated energy dissipation, and $\mathrm{Y}(\mathrm{NO})=$ quantum yield of nonregulated energy dissipation. 
By decreasing blast severity, Si helped the wheat plants preserve the functionality of the photosynthetic apparatus on their flag leaves and spikes during the infection process of $P$. oryzae. It was demonstrated that wheat plants supplied with $\mathrm{Si}$ had the functionality of their photosynthetic apparatus and gas exchange capacity increased upon infection by $P$. oryzae compared with plants not supplied with this element (Aucique-Pérez et al. 2014). In the present study, the $F_{\mathrm{v}} / F_{\mathrm{m}}$ values were less than 0.80 on flag leaves and spikes of wheat plants infected with $P$. oryzae and not supplied with $\mathrm{Si}$, suggesting the occurrence of chronic photoinhibition of photosynthesis. Indeed, the Y(II) values were lower and coupled with a progressive loss of chloroplastidic pigments, indicating that the apparent electron transport activity on infected flag leaves and spikes of plants not supplied with Si was negatively
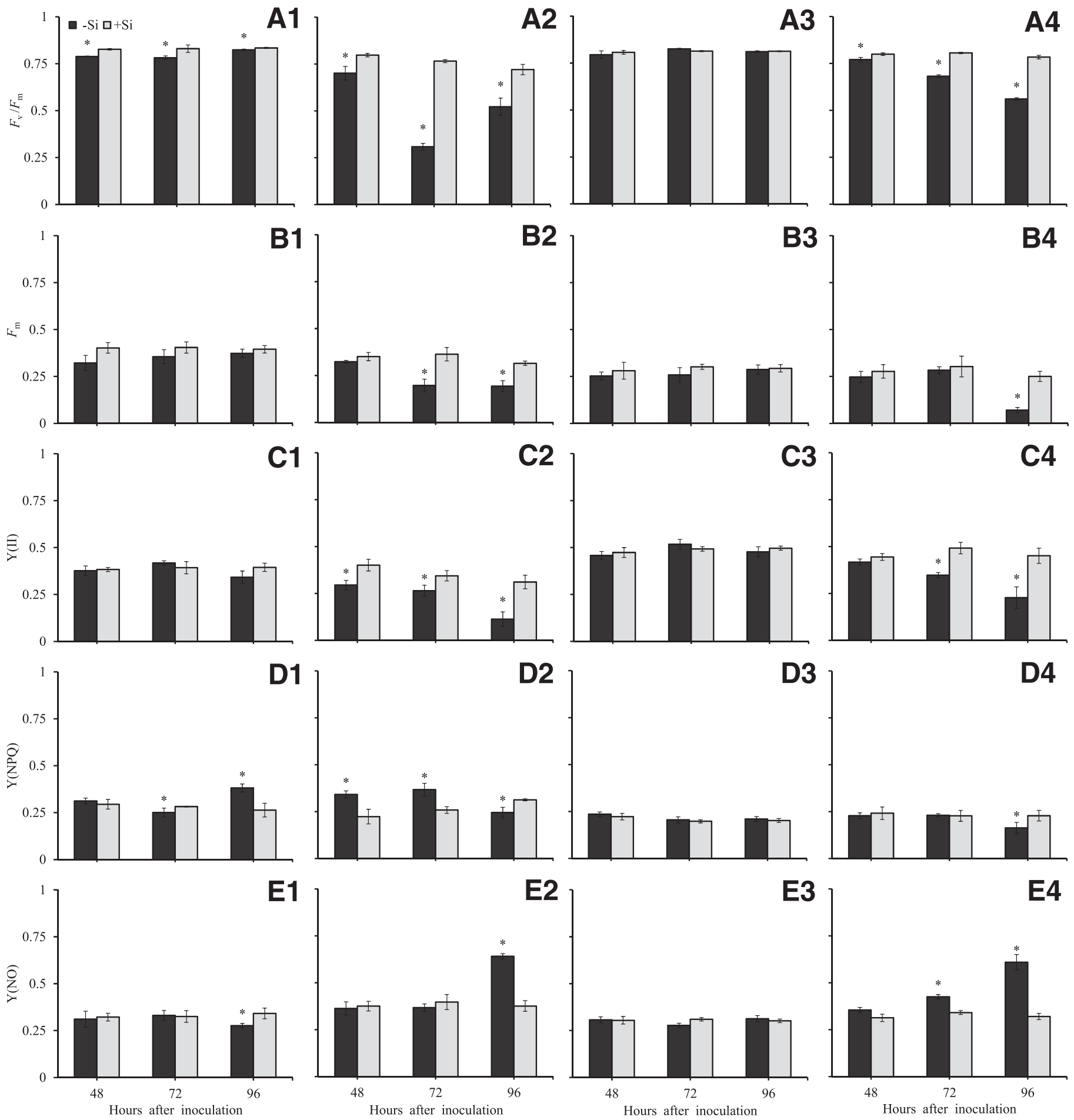

Fig. 8. Parameters of chlorophyll $a$ fluorescence $F_{\mathrm{v}} / F_{\mathrm{m}}, F_{\mathrm{m}}, \mathrm{Y}(\mathrm{II}), \mathrm{Y}(\mathrm{NPQ})$, and $\mathrm{Y}(\mathrm{NO})$ determined on A to E, flag leaves (images A1 to E1 and A2 to E2) and spikes (images A3 to E3 and A4 to E4) of wheat plants supplied with 0 or $2 \mathrm{mM}$ silicon (-Si or $+\mathrm{Si}$, respectively) and noninoculated (images A1 to E1 and $\mathrm{A} 3$ to E3) or inoculated (images A2 to E2 and A4 to E4) with Pyricularia oryzae. Means from -Si and +Si treatments followed by an asterisk, at each sampling time, are significantly different by the $F$ test $(P \leq 0.05)$. Bars represent the standard deviations of the means. $n=5 . F_{\mathrm{v}} / F_{\mathrm{m}}=$ maximal photosystem II quantum yield, $F_{\mathrm{m}}=$ maximal fluorescence, $\mathrm{Y}(\mathrm{II})=$ fraction of energy absorbed used in photochemistry, $\mathrm{Y}(\mathrm{NPQ})=$ quantum yield of regulated energy dissipation, and $\mathrm{Y}(\mathrm{NO})=$ quantum yield of nonregulated energy dissipation. 
impaired. These alterations were associated with lower and higher $\mathrm{Y}(\mathrm{NPQ})$ and $\mathrm{Y}(\mathrm{NO})$ values, respectively, which reflected the inability of plants not supplied with $\mathrm{Si}$ to regulate their mechanisms of photoprotection on flag leaves and spikes. These alterations reflected photooxidative damage on the infected host tissue that could have resulted in a lower provision of adenosine $5^{\prime}$ triphosphate and a reduced capacity for carbon dioxide assimilation (Rolfe and Scholes 2010). The reduction of photosynthesis on leaves of wheat plants infected by $P$. oryzae, based on the leaf gas exchange parameters, was attributable to biochemical constraints linked to low ribulose-1,5-bisphosphate carboxylase/ oxygenase activity (Debona et al. 2014).

Wheat plants supplied with $\mathrm{Si}$ showed great production of photoassimilates on flag leaves and their efficient partitioning to spikes was attributable to reduced disease symptoms on these organs. Given that photosynthesis was drastically constrained on infected flag leaves of plants not supplied with $\mathrm{Si}$, a lower availability of photoassimilates to be exported toward the sink
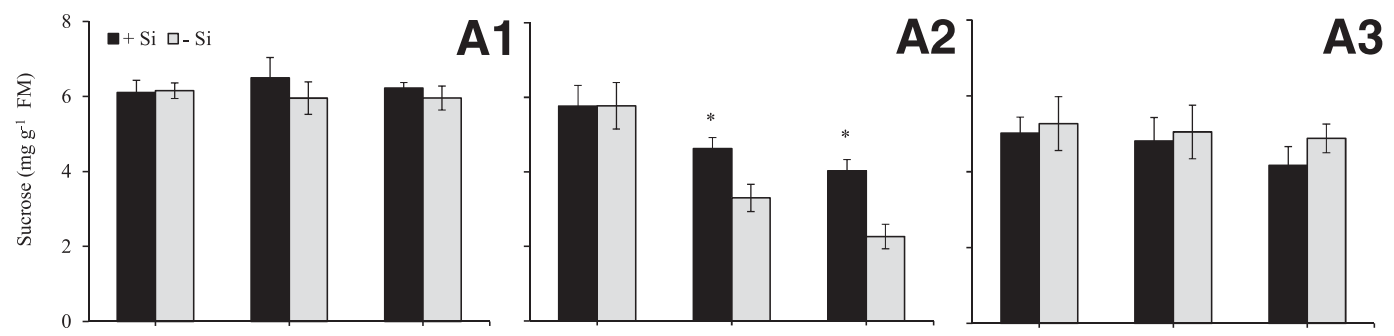

A3
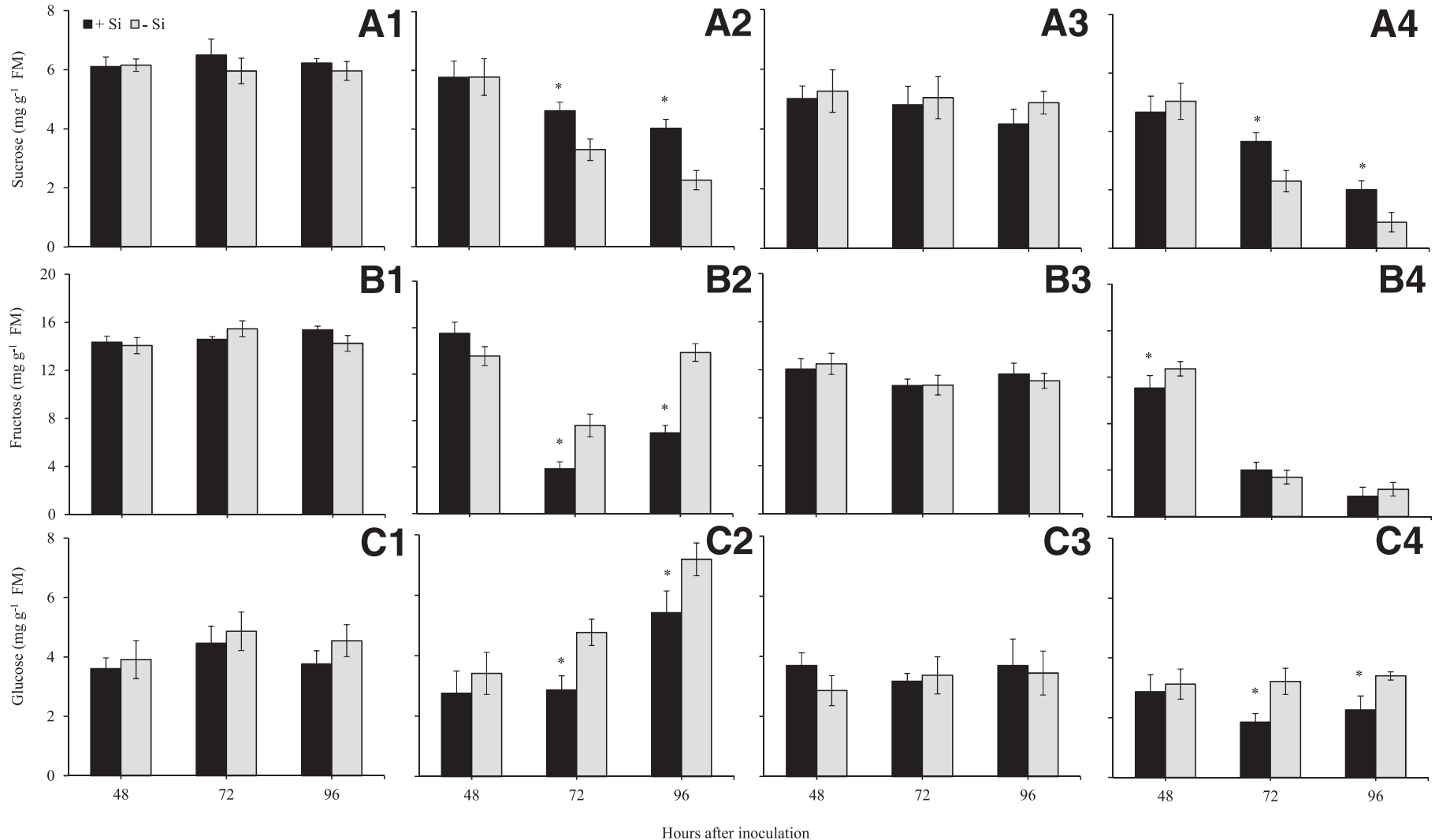

Fig. 9. A, Sucrose, B, fructose, and $\mathbf{C}$, glucose concentrations on flag leaves (images A1 to C1 and A2 to C2) and spikes (images A3 to C3 and A4 to C4) of wheat plants supplied with 0 or $2 \mathrm{mM}$ silicon $(-\mathrm{Si}$ or $+\mathrm{Si}$, respectively) and inoculated with Pyricularia oryzae. Means from $-\mathrm{Si}$ and $+\mathrm{Si}$ treatments followed by an asterisk, at each sampling time, are significantly different by the $F$ test $(P \leq 0.05)$. Bars represent the standard deviations of the means. $n=5$. FM fresh matter.

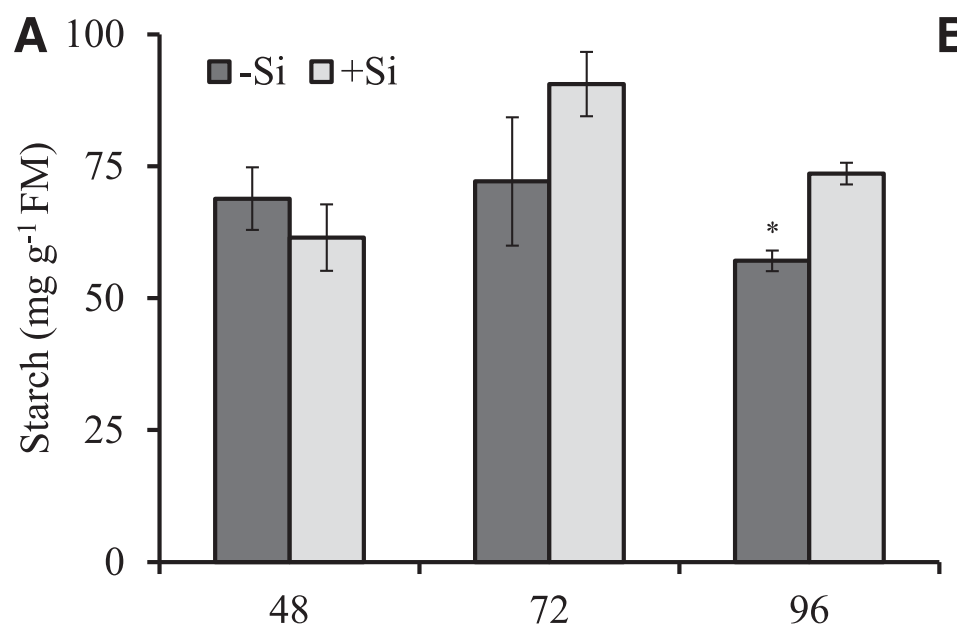

Hours after inoculation

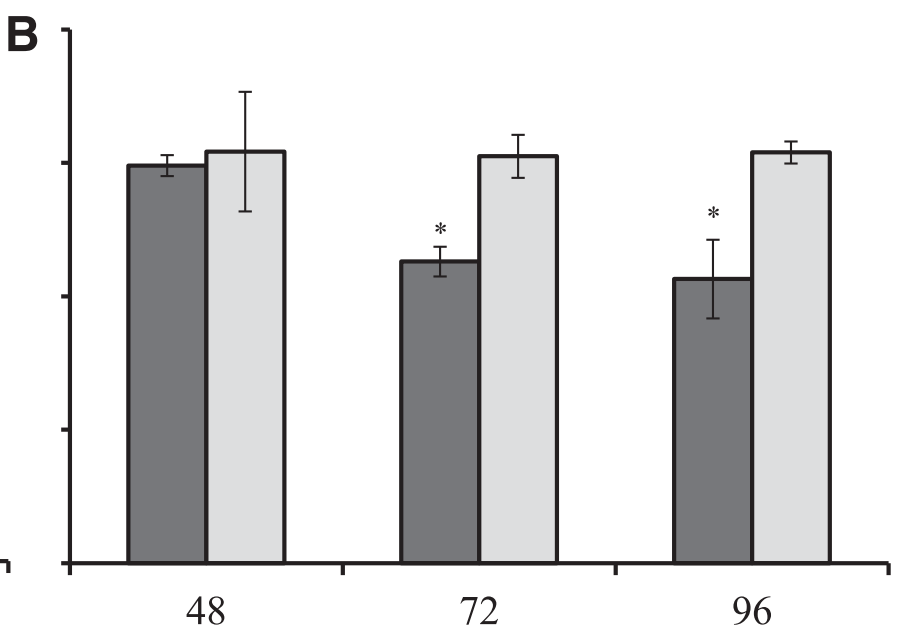

Hours after inoculation

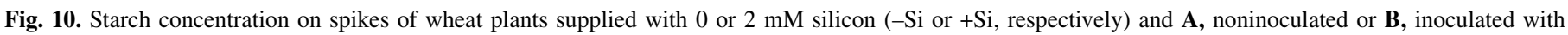

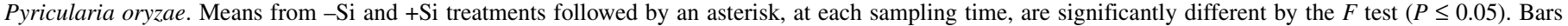
represent the standard deviations of the means. $\mathrm{FM}=$ fresh matter. $n=5$. 


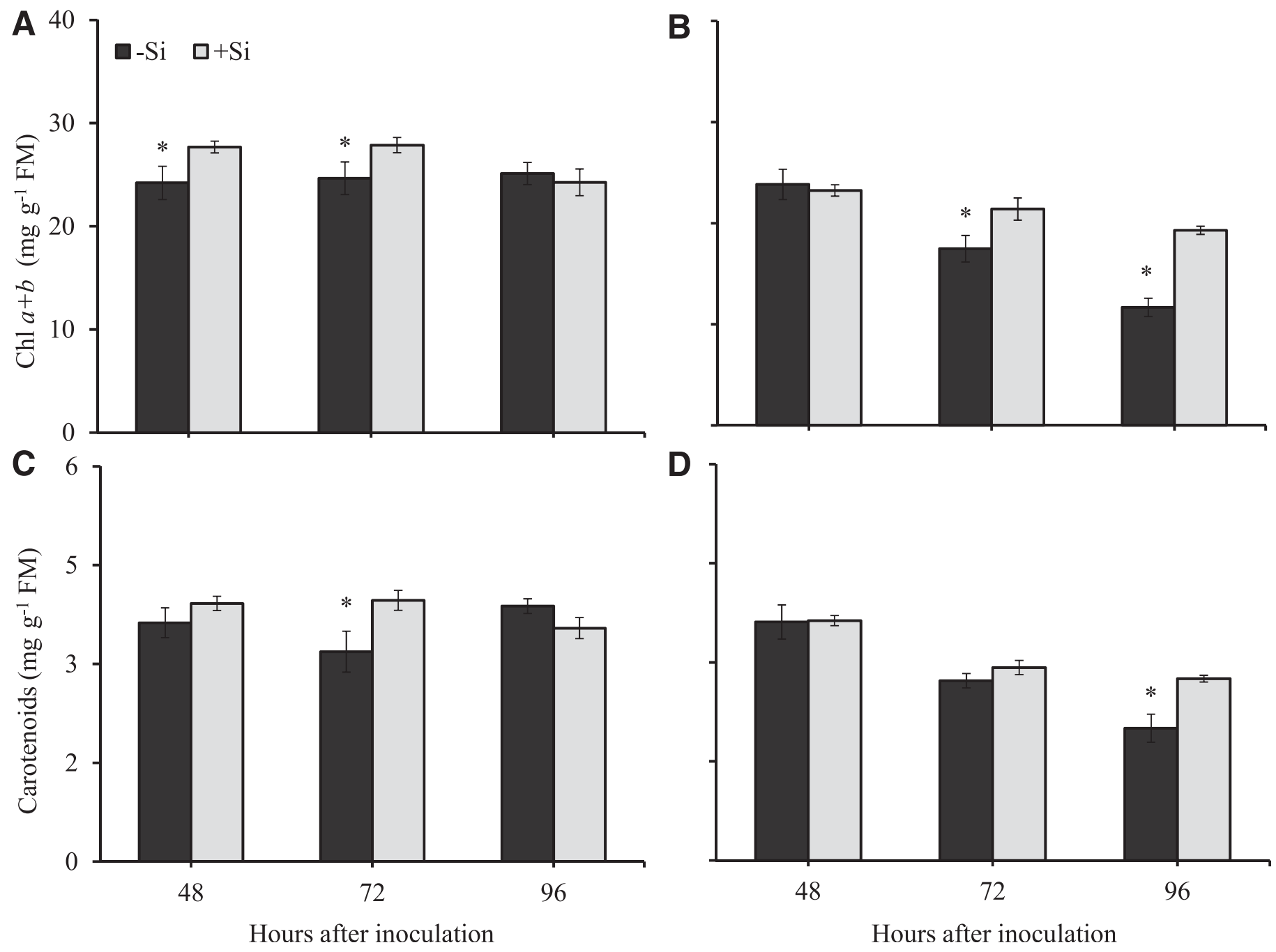

Fig. 11. Concentrations of $\mathbf{A}$ and $\mathbf{B}$, total chlorophylls $(\mathrm{Chl} a+b)$ and $\mathbf{C}$ and $\mathbf{D}$, carotenoids on flag leaves of wheat plants supplied with 0 or $2 \mathrm{mM}$ silicon (-Si or $+\mathrm{Si}$, respectively) and noninoculated ( $\mathrm{A}$ and $\mathrm{C}$ ) or inoculated (B and D) with Pyricularia oryzae. Means from $-\mathrm{Si}$ and $+\mathrm{Si}$ treatments followed by an asterisk, at each sampling time, are significantly different by the $F$ test $(P \leq 0.05)$. Bars represent the standard deviations of the means. $n=5$. FM fresh matter.

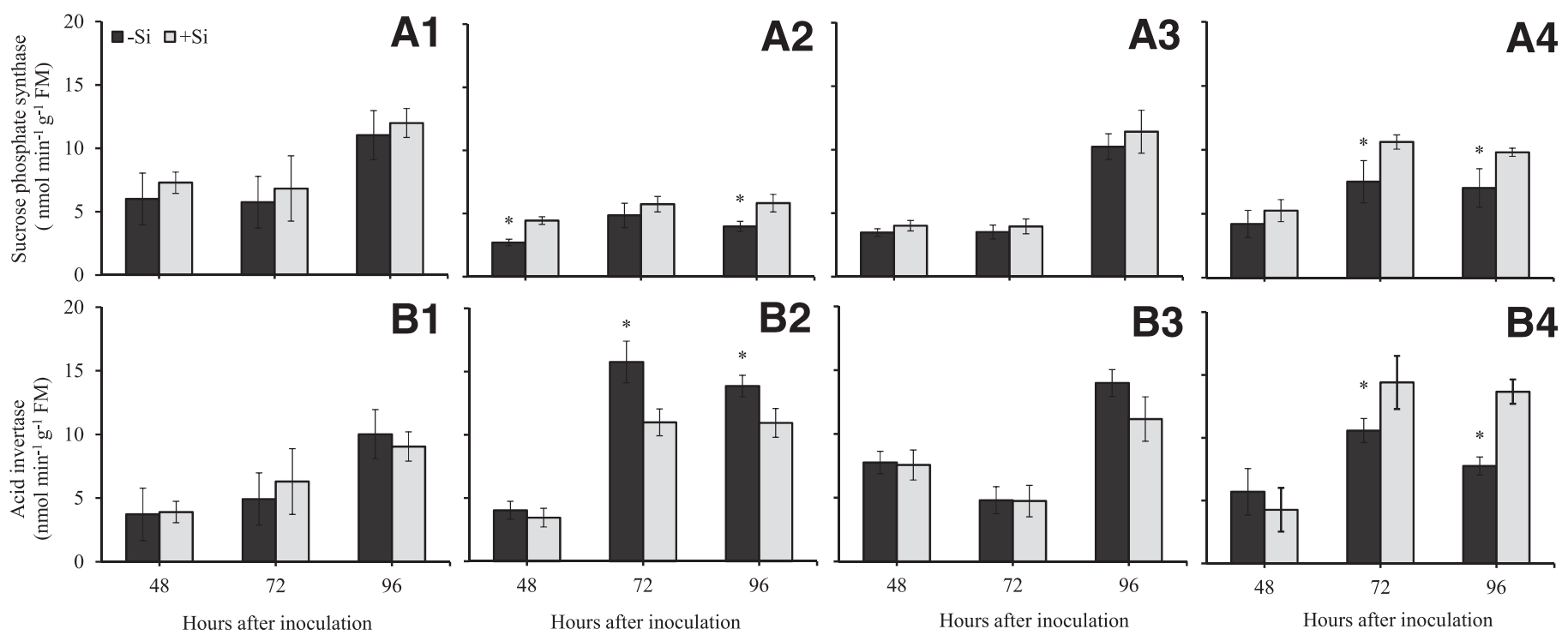

Fig. 12. Activities of A, sucrose-phosphate synthase and B, acid invertase on flag leaves (images A1, A2, B1, and B2) and spikes (images A3, A4, B3, and B4) of wheat plants supplied with 0 or $2 \mathrm{mM}$ silicon (-Si or $+\mathrm{Si}$, respectively) and noninoculated (images A1, A3, B1, and B3) or inoculated (images A2, A4, B2, and B4) with Pyricularia oryzae. Means from $-\mathrm{Si}$ and $+\mathrm{Si}$ treatments followed by an asterisk, at each sampling time, are significantly different by the $F$ test $(P \leq 0.05)$. Bars represent the standard deviations of the means. $n=5$. FM $=$ fresh matter. 
tissues was expected. Indeed, the concentration of sucrose, the main sugar form transported in plants, was lower on infected flag leaves and grains obtained from infected spikes of plants not supplied with $\mathrm{Si}$. The reduction in sucrose concentration was linked to lower SPS activity and, mainly, to an increase in acid invertase activity on infected flag leaves of plants not supplied with Si. Moreover, this contributed to depress the sucrose pools by increasing its breakdown to produce hexoses. Notably, the concentrations of fructose and glucose also increased as disease developed on flag leaves of plants not supplied with $\mathrm{Si}$ in contrast to Si-supplied plants. Consequently, the hexose-to-sucrose ratio increased as disease developed, correlating with an induction in cell wall invertase. The results of this study are in agreement with those of Berger et al. (2004) who observed an increase in the hexose-tosucrose ratio on tomato leaves infected by Pseudomonas syringae and Botrytis cinerea. Considering the information reported for other host-pathogen interactions (Gamm et al. 2011; Maust et al. 2003), but particularly for the wheat-P. oryzae interaction, the association of reduced photosynthesis with an increase in acid invertase activity for plants not supplied with Si coupled with an increase in the hexose-to-sucrose ratio suggests a sink status in the infected tissues. In addition, the increase in sucrose uptake and accumulation of hexoses may be indicative of additional sinks in plants to favor pathogen infection (Fotopoulos et al. 2003). Conversely, acid invertase activity was lower in the infected spikelets of plants not supplied with $\mathrm{Si}$ and can be linked to a decrease in the concentration of sucrose on grains obtained from spikes of plants not supplied with $\mathrm{Si}$. In this study, the starch pools dramatically decreased on grains obtained from infected spikes of plants not supplied with $\mathrm{Si}$ compared with plants supplied with this element. According to Rios et al. (2017), this effect may be associated with an impairment of adenosine 5'-diphosphate-glucose pyrophosphorylase activity (lower capacity of starch production) and higher expression of $\alpha$ and $\beta$-amylase genes (higher breakdown of starch in the infected grains).

Taken together, these alterations should remarkably impair the endosperm filling process that ultimately resulted in small and shrunken grains on the infected spikes obtained from plants not supplied with Si. Moreover, the results of this study not only support the concept that $\mathrm{Si}$ can increase wheat resistance to blast, but they also present novel evidence of its beneficial effect in improving the source-sink relationship on infected flag leaves and spikes by preserving the alterations in assimilate production and partitioning during the grain filling process.

\section{ACKNOWLEDGMENTS}

We thank R. S. Resende and P. R. Silveira for technical assistance.

\section{LITERATURE CITED}

Abood, J. K., and Losel, D. M. 2003. Changes in carbohydrate composition of cucumber leaves during the development of powdery mildew infection. Plant Pathol. 52:256-265.

Aucique-Pérez, C. E., Rodrigues, F. A., Moreira, W. R., and DaMatta, F. M. 2014. Leaf gas exchange and chlorophyll $a$ fluorescence in wheat plants supplied with silicon and infected with Pyricularia oryzae. Phytopathology 104:143-149.

Berger, S., Papadopoulos, M., Schreiber, U., Kaiser, W., and Roitsch, T. 2004. Complex regulation of gene expression, photosynthesis and sugar levels by pathogen infection in tomato. Physiol. Plant. 122:419-428.

Bradford, M. N. 1976. A rapid and sensitive method for the quantitation of microgram quantities of protein utilizing the principle of protein-dye binding. Anal. Biochem. 72:248-254.

Campbell, M. M., and Sederoff, R. R. 1996. Variation in lignin content and composition. Plant Physiol. 110:3-13.

Castroagudín, V. L., Ceresini, P. C., and Oliveira, S. C. 2015. Resistance to QoI fungicides is widespread in Brazilian populations of the wheat blast pathogen Magnaporthe oryzae. Phytopathology 105:284-294.

Ceresini, P. C., Castroagudín, V. L., Rodrigues, F. A., Rios, J. A., Aucique-Pérez, C. E., Moreira, S. I., Alves, E., Croll, D., and Maciel,
J. L. N. 2018. Wheat blast: Past, present, and future. Annu. Rev. Phytopathol. 56:427-456.

Clark, R. B. 1975. Characterization of phosphates in intact maize roots. J. Agric. Food Chem. 23:458-460.

Cruz, M. F. A., Debona, D., Rios, J. A., Barros, E. G., and Rodrigues, F. A. 2015. Potentiation of defense-related gene expression by silicon increases wheat resistance to leaf blast. Trop. Plant Pathol. 40: 394-400.

Cruz, M. F. A., Prestes, A. R., Maciel, J. L., and Scheeren, P. 2010. Resistência parcial à brusone de genótipos de trigo comum e sintético nos estádios de planta jovem e de planta adulta. Trop. Plant Pathol. 25:24-31.

Datnoff, L. E., Rodrigues, F. A., and Seebold, K. W. 2007. Silicon and plant diseases. Pages 233-246 in: Mineral Nutrition and Plant Diseases. L. E. Datnoff, W. H. Elmer, and D. M. Huber, eds. American Phytopathological Society., St. Paul, MN.

Debona, D., Rodrigues, F. A., and Datnoff, L. E. 2017. Silicon's role in abiotic and biotic plant stresses. Annu. Rev. Phytopathol. 55:85-107.

Debona, D., Rodrigues, F. A., Rios, J. A., Martins, S. C. V., Pereira, L. F., and DaMatta, F. M. 2014. Limitations to photosynthesis in leaves of wheat plants infected by Pyricularia oryzae. Phytopathology 104:34-39.

Debona, D., Rodrigues, F. A., Rios, J. A., and Nascimento, K. J. T. 2012. Biochemical changes in the leaves of wheat plants infected by Pyricularia oryzae. Phytopathology 102:1121-1129.

Doehlert, D. C., and Huber, S. C. 1983. Regulation of spinach leaf sucrose phosphate synthase by glucose-6-phosphate, inorganic phosphate and $\mathrm{pH}$. Plant Physiol. 73:989-994.

Fernie, A. R., Roscher, A., Ratcliffe, R. G., and Kruger, N. J. 2001. Fructose 2,6bisphosphate activates pyrophosphate: Fructose-6-phosphate 1-phosphotransferase and increases triose phosphate to hexose phosphate cycling in heterotrophic cells. Planta 212:250-263.

Fotopoulos, V., Gilbert, M. J., Pittman, J. K., Marvier, A. C., Buchanan, A. J., and Sauer, N. 2003. The monosaccharide transporter gene, AtSTP4, and the cell-wall invertase, Atbfruct1, are induced in Arabidopsis during infection with the fungal biotroph Erysiphe cichoracearum. Plant Physiol. 132: 821-829.

Gamm, M., Héloir, M. C., Bligny, R., Vaillant-Gaveau, N., Trouvelot, S., Alcaraz, G., Frettinger, P., Clément, C., Pugin, A., Wendehenne, D., and Adrian, M. 2011. Changes in carbohydrate metabolism in Plasmopara viticola-infected grapevine leaves. Mol. Plant-Microbe Interact. 24: 1061-1073.

Gibon, Y., Blaesing, O. E., Hannemann, J., Carillo, P., Höhne, M., Hendriks, J. H., Palacios, N., Cross, J., Selbig, J., and Stitt, M. 2004. A robot-based platform to measure multiple enzyme activities in Arabidopsis using a set of cycling assays: Comparison of changes of enzyme activities and transcript levels during diurnal cycles and in prolonged darkness. Plant Cell 16: 3304-3325.

Ma, J. F., Tamai, K., Ichii, M., and Wu, G. F. 2002. A rice mutant defective in Si uptake. Plant Physiol. 130:2111-2117.

Mauch, F., Mauch-Mani, B., and Boller, T. 1988. Antifungal hydrolases in pea tissue. Inhibition of fungal growth by combinations of chitinase and $\beta-1,3-$ glucanase. Plant Physiol. 88:936-942.

Maust, B. E., Espadas, F., Talavera, C., Aguilar, M., Santamaría, J. M., and Oropeza, C. 2003. Changes in carbohydrate metabolism in coconut palms infected with the lethal yellowing phytoplasma. Phytopathology 93: 976-981.

Nunes-Nesi, A., Carrari, F., Gibon, Y., Sulpice, R., Lytovchenko, A., Fisahn, J., Graham, J., Ratcliffe, R. G., Sweetlove, L. J., and Fernie, A. R. 2007. Deficiency of mitochondrial fumarase activity in tomato plants impairs photosynthesis via an effect on stomatal function. Plant J. 50:1093-1106.

Praxedes, S. C., DaMatta, F. M., Loureiro, M. E., Ferrão, M. A. G., and Cordeiro, A. T. 2006. Effects of long-term soil drought on photosynthesis and carbohydrate metabolism in mature robusta coffee (Coffea canephora Pierre var. kouillou) leaves. Environ. Exp. Bot. 56:263-273.

Resende, R. R., Rodrigues, F. A., Soares, J. M., and Casela, C. R. 2009. Influence of silicon on some components of resistance to anthracnose in susceptible and resistant sorghum lines. Eur. J. Plant Pathol. 124: 533-541.

Rios, J. A., Debona, D., Duarte, H. S. S., and Rodrigues, F. A. 2013. Development and validation of a standard area diagram set to assess blast severity on wheat leaves. Eur. J. Plant Pathol. 136:603-611.

Rios, J. A., Rios, V. S., Aucique-Pérez, C. E., Cruz, M. F. A., Morais, L. E., DaMatta, F. M., and Rodrigues, F. A. 2017. The photosynthetic performance and source-sink relationships are altered on wheat plants infected by Pyricularia oryzae. Plant Pathol. 66:1496-1507.

Rodrigues, F. A., Jurick, W. M., Datnoff, L. E., Jones, J. B., and Rollins, J. A. 2005. Silicon influences cytological and molecular events in compatible and incompatible rice-Magnaporthe grisea interactions. Physiol. Mol. Plant Pathol. 66:144-159. 
Rolfe, S. A., and Scholes, J. D. 2010. Chlorophyll fluorescence imaging of plant-pathogen interactions. Protoplasma 247:163-175.

Santos, R. P., Cruz, A. C. F., Iarema, L., Kuki, K. N., and Otoni, W. C. 2008. Protocolo para extração de pigmentos foliares em porta-enxertos de videira micropropagados. Ceres 55:356-364.

Southerton, S. G., and Deverall, B. J. 1990. Histochemical and chemical evidence for lignin accumulation during the expression of resistance to leaf rust fungi in wheat. Physiol. Mol. Plant Pathol. 36:483-494.

Tambussi, E. A., Bort, J., Guiamet, J. J., Nogués, S., and Araus, J. L. 2007. The photosynthetic role of ears in C3 cereals: Metabolism, water use efficiency and contribution to grain yield. Crit. Rev. Plant Sci. 26:1-16.
Tatagiba, S. D., Rodrigues, F. A., Filippi, M. C. C., Silva, G. B., and Silva, L. C. 2014. Physiological responses of rice plants supplied with silicon to Monographella albescens infection. J. Phytopathol. 162: 596-606.

Tuncel, A., and Okita, T. W. 2013. Improving starch yield in cereals by overexpression of ADPglucose pyrophosphorylase: Expectations and unanticipated outcomes. Plant Sci. 211:52-60.

Zadoks, J. C., Chang, T. T., and Konzak, C. F. 1974. A decimal code for the growth stages of cereals. Weed Res. 14:415-421.

Zeeman, S. C., Smith, S. M., and Smith, A. M. 2007. The diurnal metabolism of leaf starch. Biochem. J. 401:13-28. 